Available online on 15.06.2020 at http://ajprd.com
(c) 2013-20, publisher and licensee AJPRD, This is an Open Access article which permits unrestricted non-
commercial use, provided the original work is properly cited

Open $\odot$ Access

Review Article

\title{
Spherical Crystallization: A Tool to Improve the Physicochemical Properties of APIs
}

\author{
R. R. Thenge, M. P. Chandak*, V. S. Adhao \\ Dr. Rajendra Gode College of Pharmacy, Malkapur-443101, Maharashtra, India
}

\begin{abstract}
A B S T R A C T
A greater challenge in solid dosage formulation is the development of spherical agglomerates which increases the solubility and bioavailability of the drug. Spherical crystallization is "An agglomeration process that transforms crystals directly into compact spherical forms during the crystallization process." Spherical crystallization is the novel agglomeration technique that can transform directly the fine crystals produced in the crystallization process into a spherical shape. Direct Compression of powders is simple and easy way of making tablets. In direct compression of Good Compressibility and flowability plays a major role. Spherical crystallization methods are very useful methods in which the drug crystals are modified using different solvents to directly compressible agglomerates. which cost effective and time saving. The different Techniques discussed are Crystallization method, Solvent crystallization method, Quasi- emulsion diffusion method, Ammonia Diffusion method, neutralization method, and solvent agglomeration technique. This article gives a detailed and comprehensive review about different techniques, its advantages, mechanism and application of Spherical agglomeration Technique along with its Evaluation and Characterization methods.
\end{abstract}

Keywords: Spherical Crystallization, Evaluation, Novel drug delivery system.

A R T I C L E I N F 0: Received 16 March 2020; Review Completed 05 may 2020; Accepted 12 May 2020; Available online 15 June. 2020

Cite this article as:

Thenge R R, Chandak M P, Adhao V S, Spherical Crystallization: A Tool to Improve the Physicochemical Properties of APIs, Asian Journal of Pharmaceutical Research and Development. 2020; 8(3):105- 111. DOI: http://dx.doi.org/10.22270/ajprd.v8i3.727

*Address for Correspondence:

M. P. Chandak, Dr. Rajendra Gode College of Pharmacy, Malkapur-443101, Maharashtra, India

\section{INTRODUCTION:}

$\mathrm{T}$ Tablet is very specific dosage form, accounting for 50 $\%$ of all oral drug delivery system and $70 \%$ of all pharmaceutical preparations produced ${ }^{1}$. Formulation and manufacture of solid dosage forms and tablets especially, have undergone rapid change and development over several decades. One of the revolutionary technologies is of direct compression ${ }^{2}$. Direct compression involves simple mixing and compression of powders which is economical and time saving ${ }^{3}$. Compressing a drug directly requires good micromeritic properties, like flowability, and an honest reproducible compressibility. Especially, the flowability of needle-shaped or plated-shaped crystals is very poor and these crystals are difficult to handle ${ }^{4}$.In addition to increasing efficiency of manufacturing process it is also important to increase the bioavailability of drug by increasing solubility of bulk drug powder ${ }^{5}$.Developing novel methods to increase the bioavailability of drugs that inherently have poor aqueous solubility is a great challenge to solid dosage form formulators. Mechanical micronization of crystalline drugs and incorporation of surfactants during the crystallization process are the techniques commonly used to improve the bioavailability of poorly soluble drugs ${ }^{2,3}$.Spherical crystallization is a particle design technique, by which crystallization and agglomeration can be carried out simultaneously in one step and which has been successfully utilized for improvement of flowability and compactability of crystalline drugs Spherical crystallization transforms crystals directly in to a compact spherical forms during the crystallization process. It also enables co-precipitation of drug and encapsulating polymer in the form of spherical particle $^{6}$.

\section{Need for Spherical Crystallization:}

Developing novel methods to extend the bioavailability of medicine that inherently have poor aqueous solubility is great challenge to formulate solid dosage form. Mechanical micronization of crystalline drugs and incorporation of surfactants during the crystallization process are the techniques commonly want to improve the bioavailability 
of poorly soluble drugs. The mirconization process alters the flow and compressibility of crystalline powders and cause formulation problems. Addition of surfactant generally led to smaller increase in aqueous solubility. to beat this problem Kawashima developed a spherical crystallization technique that led to improving the flow and direct compressibility of number of microcrystalline drugs 7,8

\section{Advantages: ${ }^{9}$}

- Physicochemical properties of pharmaceutical crystals are mainly improved for pharmaceutical process i.e. milling, mixing and tabletting by using this system.

- The micromeritic properties of the drug crystal shall be drastically improved.

- Utilization of this process improves wettability and dissolution rate of some drugs.

- Use of this system results in conversion of crystalline sorts of a drug into polymorphic form which will have better bioavailability.

- This technique could enable subsequent processes like separation, filtration, drying, etc. to be administered more efficiently.

- Preparation of microsponges, microspheres and nanospheres, microballoons, nanoparticles and micro pellets as novel particulate drug delivery system is feasible by it.

- It are often used for masking of the bitter taste of drug.

Disadvantages: ${ }^{9}$

- Selection of suitable solvents is a tedious process.

- Optimization of processing parameters (temperature, agitation) is difficult.

\section{METHODS OF SPHERICAL CRYSTALLIZATION:}

Spherical crystals can be obtained by two different techniques, either by typical spherical crystallization technique or non-typical spherical crystallization technique $^{11}$. Non typical spherical crystallization technique can also be considered as the traditional crystallization process (salting-out, cooling, precipitation, etc.).

The two most commonly used techniques of spherical crystallization are wet spherical agglomeration method (WSA), quasi-emulsion solvent diffusion method (QESD, Transient emulsion $)^{10}$. But there are two extensions of these techniques, ammonia diffusion system (ADS) and crystalco-agglomeration technique (CCA) ${ }^{12,13 .}$ Another technique of this process is Neutralization, where first fine crystals form by neutralization then it will agglomerate by the help of a bridging liquid ${ }^{14}$.

Following methods are used to prepare the spherical crystals:

- Spherical Agglomeration method (SA)

- Quasi-Emulsion Solvent Diffusion method (QESD)

- Ammonia diffusion system (ADS)

- Neutralization Technique (NT)

- Traditional Crystallization Process(TCP)

- Crystal-co-agglomeration Technique(CaT)

Spherical Agglomeration Method (SA):

This method involves simultaneous crystallization and agglomeration of two or more drugs from an honest solvent and bridging liquid by addition of a non-solvent. to get fine crystals the answer of the drug and an honest solvent is poured into a poor solvent under controlled condition of temperature and speed. The bridging liquid is employed for agglomeration of the crystals ${ }^{15}$.

Here the good and thus the poor solvents are freely miscible and interaction (binding force) between the solvents is stronger than drug interaction with the good solvent, which ends up in precipitation of crystals immediately ${ }^{10}$. Bridging liquid collects the crystals suspended within the system by forming liquid bridges between the crystals because of capillary negative pressure and interfacial physical phenomenon between the interface of solid and liquid ${ }^{11}$.SA method proceeds in three steps as shown in Fig.1

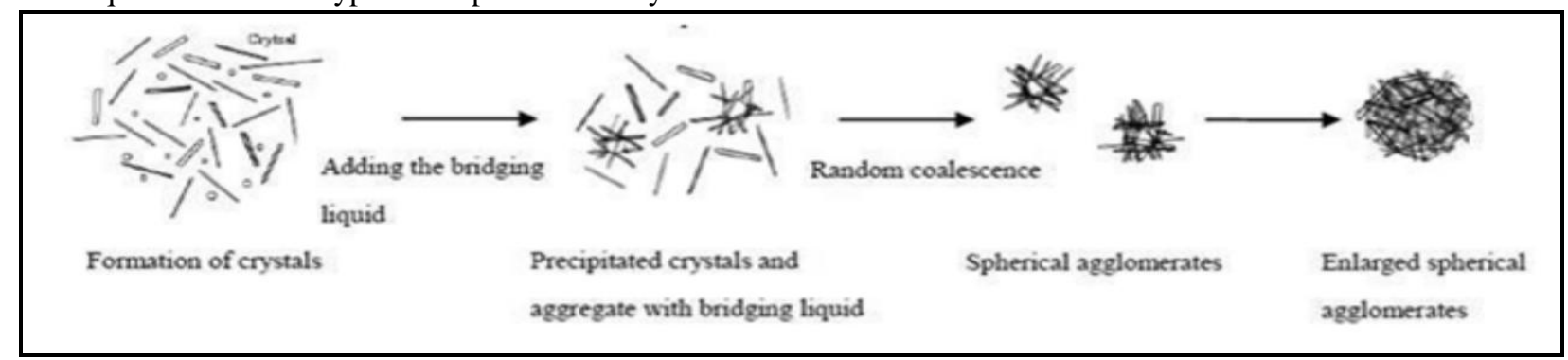

Figure: 1Steps Involved in Spherical Agglomeration (SA)

The first step is that the selection of the crystallization method to precipitate crystals from solution, i.e., thermal method (temperature decrease or evaporation), physicochemical methods (addition of another solvent, salting out) and reaction. The second step is that the choice of the wetter which will be immiscible with the solvent of crystallization. Finally, the third step is that the hardening of the agglomerates. The disadvantage of this technique is that it provides low yield, thanks o co-solvency effect of crystallization solvent. The bridging liquid, the stirring speed and therefore the concentration of solids are the influencing factors for the spherical crystallization ${ }^{15}$.

\section{Quasi Emulsion Solvent Diffusion Method:}

In the case of quasi emulsion solvent diffusion method, affinity between the drug and a good solvent is stronger than that of the drug and poor solvent. Residual good solvent in droplets acts as a bridging liquid to agglomerate the generated crystals. Due to the interfacial tension between the two solvents, the good solvent diffuses gradually out of the emulsion droplet into the outer poor solvent phase as given in Fig.2 


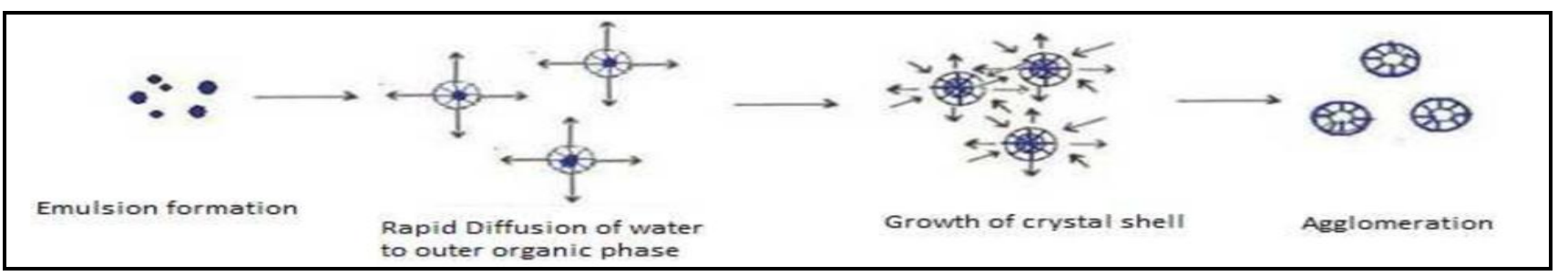

Figure: 2 Mechanism of Quasi Emulsion Solvent Diffusion Method

The crystallization of drug happens by counter diffusion of excellent solvent and poor solvent.

During this method, the emulsion is stable by the choice of appropriate chemical compound that is needed for correct crystallization. within the droplets, the method of curing takes inwards and therefore the liquid don't seem to be maintained on the surface and therefore the agglomerate shaped while not union ${ }^{10}$.

\section{Ammonia Diffusion Method (ADM)}

In this technique ammonia-water system is employed because the smart solvent and unhealthy solvent is chosen relying upon the medication solubility in this solvent. The ammonia-water conjointly acts as a bridging liquid. this system typically meant for amphiprotic medication that cannot be collective by typical procedures. the full method is completed in 3 stages $^{13}$. First, the drug dissolved in ammonium hydroxide is precipitated whereas the droplets collect the crystals. at the same time, ammonia within the agglomerate diffuses to the outer organic solvent.

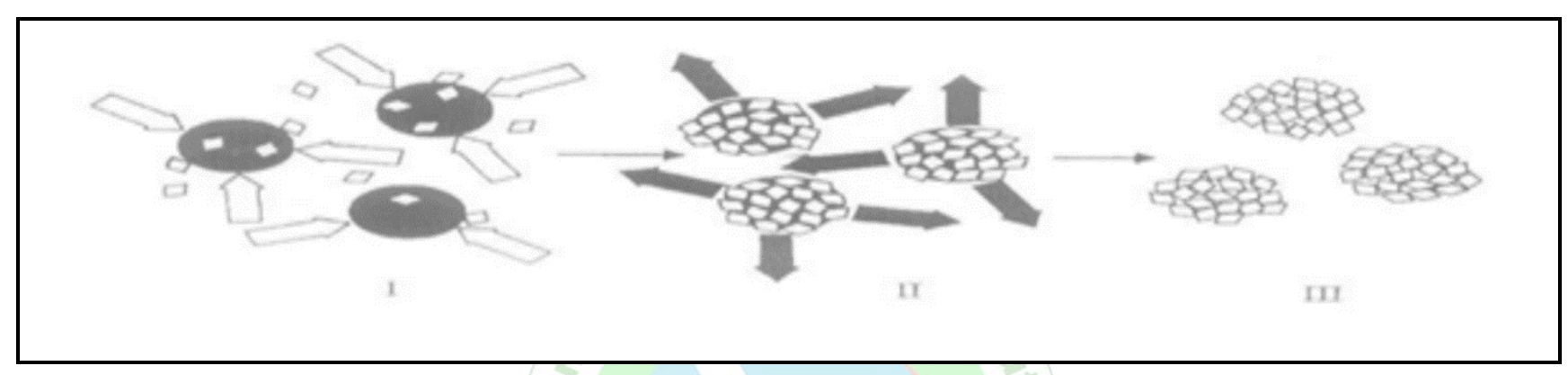

Figure: 3 Steps involved in Ammonia Diffusion Method (ADM): (I) Drug Precipitation (II) Ammonia Diffusion (III) Spherical Agglomeration

\section{Neutralization Method:}

The method consists of dissolving the drug in the good solvent and placing in the cylindrical vessel with constant stirring. During stirring an aqueous polymer solution and one neutral solution was added to neutralize the good solvent, which crystallizes out the drug. The bridging liquid shall be added drop wise at a definite rate. The agglomeration of the crystal form of the drug takes place ${ }^{15}$.

\section{Traditional Crystallization Process:}

Spherical agglomerates shall be produced in these methods by controlling the physical and chemical properties and can be called as the non-typical spherical crystallization processes.

\section{Crystal-co-agglomeration Technique (CCA)}

Applications of spherical crystallization to obtain directly compressible agglomerates without diluents are restricted to water insoluble large-dose drugs only. Most of the excipients, such as diluents and disintegrating agents, are hydrophilic in nature; hence, incorporation of these excipients in the agglomerates formed using organic bridging liquid is difficult. Because of this limitation, spherical crystallization could not be applied to obtain agglomerates of low-dose or poorly compressible materials $^{13}$.

To overcome these limitations of spherical crystallization Kadam et al. developed the crystal-co-agglomeration (CCA) technique. It is a modification of the spherical crystallization technique in which a drug is crystallized and agglomerated with excipients or with another drug, which may or may not be crystallized in the system. The agglomeration is performed using bridging liquid. The process enables design of agglomerates containing two drugs ${ }^{13}$ or a low-dose or poorly compressible drug in combination with diluents. The difference in the physicochemical properties of the drug molecules and the excipients becomes the major challenge in the selection of a solvent system for the crystal-co-agglomeration.

\section{Steps involved in the process of spherical crystallization:}

Flocculation zone, zero growth zone, fast growth zone and constant size zone ${ }^{16}$.

\section{Flocculation zone}

In this zone, bridging liquid displaces the liquid from the surface of the crystals and these crystals arebrought in close proximity by agitation. The adsorbed bridging liquid links the particles by forming bridge between them.

\section{Zero growth zone}

During this growth phase, the entrapped fluid is squeezed out followed by squeezing of the bridging liquid onto the surface of small flocks. Loose floccules are transformed into tightly packed pellets

\section{Fast growth zone}

The fast growth zone of the agglomerate takes place when sufficient bridging liquid has squeezed out of the surface of the small agglomerates. This formation of large size particle after random collision of well-formed nucleus is known as coalescence.

\section{Constant size zone}

In this zone agglomerates cease to grow or even show slight decrease in size. Here the frequency of coalescence is 
balanced by the breakage frequency of agglomeration. The rate determining step in agglomeration growth occurs in zero growth zones when bridging liquid is squeezed out of the pores as the initial floccules are transformed into small agglomerates.

\section{Factors controlling the process of agglomeration: ${ }^{17}$}

\section{Solubility profile}

Selection of solvent depends upon the solubility characteristics of the drug. The proportion of solvent to be used is determined by carrying out solubility studies and constructing a ternary phase diagram.

\section{Mode and intensity of agitation}

High speed agitation is necessary to disperse the bridging liquid throughout the system. Change in the agitation pattern or fluid flow will affect the shape of agglomerates. The extent of mechanical agitation and the concentration of bridging liquid determine the rate of formation of agglomerates and their final size.

\section{Temperature of the system}

It has a significant influence on the shape, size and texture of the agglomerates. The effect of temperature on spherical crystallization is probably due to its effect on the solubility of drug substance.

\section{Residence time}

It is defined as the time for which agglomerates remain suspended in the reaction mixture. Residence time affects the strength of agglomerates.

\section{Amount of bridging Liquid}

Median diameter of agglomerated crystals increases with decrease in the amount of bridging liquid in the threesolvent system. Insufficient bridging liquid produces plenty of fines and excess produces very coarse particles ${ }^{18}$.

The common excipients used in spherical crystallization (polymers and surfactants):

Presence of additives like polymers and surface-active agents whose surfaces are not similar to the crystal surfaces can influence molecular aggregation during crystallization. The viscosity of the medium and surface tension is reduced by the surfactants which affect the nucleation process. Studies have revealed that crystallization and agglomeration of pure drugs shows poor compressibility and handling qualities. Addition of polymers such as HPMC, PEG and PVP has improved the properties of spherical agglomerates.

\section{EVALUATION OF SPHERICAL AGGLOMERATES:}

\section{Micromeritic properties}

Improvement in the flowability of agglomerates could be attributed to thesignificant reduction in inter-particle friction due to their spherical shape and lower static electric charge $^{19}$.

Methods used for determination of flow properties are:

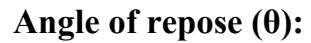

It can be obtained from the equation:

$\theta=\tan -1 \mathbf{h} / \mathbf{r}$
Where, $\mathrm{h}=$ height of the cone.

$\mathrm{r}=\mathrm{is}$ radius of cone.

Values for angle of repose: $\leq 30$ indicate free flow and $\geq 40$ indicate poor flow.

\section{Compressibility or Carrs index:}

Compressibility index calculated by:

$\mathrm{I}=(\mathbf{1 - V} / \mathrm{Vo}) \mathbf{1 0 0}$

Where, $\mathrm{V}=$ Volume occupied by a sample of the powder after being subjected to standardized tapping procedure

$\mathrm{Vo}=$ The volume before tapping.

Value below $15 \%$ indicates good flowability and value above $25 \%$ indicate poor flowability

\section{Hausner ratio:}

It is calculated from bulk density and tap density.

\section{Hausner ratio $=$ Tapped density $/$ Bulk density}

Values less than 1.25 indicate good flow and the value greater than 1.25 indicates poor flow.

\section{Friability test:}

Tak Ho and John A Hersy method is used and determined by formula

\section{Friability $(X)=\{1-W / W o\} / 100$}

Where,

Wo = Initial weight of the crystalline agglomerates placed in sieve

$\mathrm{W}=$ Weight of the material retained on sieve after 5 minutes.

\section{Mechanical Properties:}

Tensile strength of spherical agglomerates is determined by compressing $500 \mathrm{mg}$ of crystals using hydraulic press at different forces $(\mathrm{kg} / \mathrm{cm} 2)$ for $1 \mathrm{~min}$. The hardness of each compact is measured using Pfizer hardness tester. Crushing strength of agglomerates is determined by using modified Jarosz and Parrot's mercury load cell method ${ }^{20}$.

\section{Wettability:}

- Wettability depends on the crystallinity and elementary crystal size of the agglomerated crystals. The methods used to determine wettability are:

- Determination of density: Density of saturated solution of drug and spherical crystals in water is determined by using a relative density bottle.

- Determination of surface tension: Surface tension of saturated solution of drug and spherical crystals in water is determined by employing a stalagmometer.

- Determination of porosity: Thickness and diameter of prepared tablet of drug spherical crystals is determined by using vernier callipers. Porosity of tablet is calculated from the apparent density of the tablet.

\section{Solubility studies:}

Solubility studies are carried out in distilled water and dissolution medium by using Flask shaker method. 
Spherical agglomerated crystals are introduced into a flask containing distilled water and dissolution medium. The flasks are shaken for 24 hours at room temperature. The filtrates are then diluted with the respective medium and content is determined by a suitable analytical ${ }^{21}$.

\section{Dissolution studies:}

Dissolution of spherical agglomerates is determined by using the official dissolution apparatus and comparative studies are done for agglomerated crystals and nonagglomerate $^{22}$. Dissolution rate and bioavailability depends on the particle size and density and specific surface area of the agglomerated crystals.

\section{Particle Size and Size Distribution:}

Size of the particle and their distributions can be determined by simple sieve analysis with the help of a RoTap sieve shaker.

\section{Compression Behavior Analysis:}

Good compatibility and compressibility are the essential properties of directly compressible crystals. The compaction behavior of agglomerated crystals and single crystals is obtained by plotting the relative volume against the compression pressure. Compaction behavior of agglomerated crystals can be evaluated by using following parameters:

\section{Heckel Analysis}

The following Heckel's equation is used to analyze the compression process of agglomerated crystals and assessed their compatibility.

\section{In $[1 /(1-D)]=K P+A$}

Where,

$\mathrm{D}$ is the relative density of the tablets under compression Pressure and $\mathrm{K}$ is the slope of the straight portion of the Heckel Plot.

\section{Moisture uptake study:}

This study indicates the behaviour of uptake of moisture by drug and the prepared spherical crystals which affects their stability. Weighed quantity of drug and spherical crystals are placed in crucibles at accelerated conditions of temperature and humidity, $400 \mathrm{C} \pm 10 \mathrm{C}$ and $75 \% \pm 3 \%$ respectively. Gain in weight of drug and spherical crystals is measured ${ }^{23}$.

\section{Application: $:^{2,22}$}

- Spherical crystallization used for improvement of

- Dissolution

- Bioavailability

- Flowablity

- Compressibility

- Stability

- Toxicity

- For masking bitter taste of drug

Table: 1 Drug formulated in the form of spherical crystal and their uses.

\begin{tabular}{|c|c|c|c|c|c|}
\hline Sr no. & Drug & 6 & Techniques & $\begin{array}{l}\text { Use } \\
\end{array}$ & Reference \\
\hline 1 & Enoxacin & & $\mathrm{ADM}$ & Antibiotics Activity & 24 \\
\hline 2 & Ampicillin Trihydrate & 6 & $\mathrm{ADM}$ & Antibiotics Activity & 25 \\
\hline 3 & Norfloxacin & & $\mathrm{ADM}$ & Antibiotics Activity & 26 \\
\hline 4 & Cefuroxime Axetil & & QESD & Antibiotics Activity & 27 \\
\hline 5 & Roxythromycin & & SA & Antibiotics Activity & 28 \\
\hline 6 & Aspirin & & SA & NSAIDS Activity & 29 \\
\hline 7 & Aceclofenac & & SA & NSAIDS Activity & 30 \\
\hline 8 & Acetylsalicyclic acid & & SA & NSAIDS Activity & 31 \\
\hline 9 & Celocoxib & & SA & NSAIDS Activity & 24 \\
\hline 10 & Flubiprofen & & SA & NSAIDS Activity & 32 \\
\hline 11 & Fenbufen & & SA & NSAIDS Activity & 33 \\
\hline 12 & Ibuprofen & & SA & NSAIDS Activity & 34 \\
\hline 13 & Ibuprofen-Paracetamol & & $\mathrm{CCA}$ & NSAIDS Activity & 35,36 \\
\hline 14 & Ibuprofen-Talc & & CCA & NSAIDS Activity & 37 \\
\hline 15 & Indomethacin & & SA & NSAIDS Activity & 38 \\
\hline 16 & Indomethacin Mepirizole & & CCA & NSAIDS Activity & 39 \\
\hline 17 & Ketoprofen & & QESD & NSAIDS Activity & 40 \\
\hline 18 & Ketoprofen-Talc & & CCA & NSAIDS Activity & 41 \\
\hline 19 & Mefenamic acid & & $\mathrm{ADM}$ & NSAIDS Activity & 42 \\
\hline 20 & Naproxen & & CCA & NSAIDS Activity & 43 \\
\hline 21 & Nabumetone & & SA & NSAIDS Activity & 44 \\
\hline 22 & Piroxicam & & NT & NSAIDS Activity & 45 \\
\hline 23 & Propylphenazone & & ESD & NSAIDS Activity & 46 \\
\hline 24 & Aminophylline & & SA & Bronchodialators Activity & 47 \\
\hline
\end{tabular}




\begin{tabular}{|l|l|l|l|l|}
\hline 25 & Theophylline & SA & Bronchodialators Activity & 48 \\
\hline 26 & Glibenclamide & QESD & Antidiabetic Activity & 49 \\
\hline 27 & Tolbutamine & QESD,NT & Antidiabetic Activity & 50 \\
\hline 28 & Acebutalol HCl & ESD & ß-adrenergic blocker activity & 51 \\
\hline 29 & Gresiofulvin & ESD & Antifungal Activity & 52 \\
\hline 30 & Tranilast & SA & Antiallergic Activity & 53 \\
\hline 31 & Valsartan & ESD & Antihypertensive Activity & 54 \\
\hline 32 & Mebandazole & SA & Antihelmenthic drugs & 55 \\
\hline
\end{tabular}

$\mathrm{SA}=$ Spherical Agglomeration, ESDS = Quasi-Emulsion Solvent Diffusion System, ADS = Ammonia Diffusion System, NT = Neutralization Technique, $\mathrm{CCA}=$ Crystal-co-agglomeration technique

\section{CONCLUSION:}

Spherical crystallization reduces time and cost by enabling faster operation, less machinery and fewer personnel because of less number of the steps when compared to conventional granulation technology of tablet manufacturing. But the residues of organic solvent after the formation of agglomerates have to be monitored for passing the regulatory requirements. Agglomerates exhibit

\section{REFERENCES:}

1. Rasmuson CA, Katta J. Spherical crystallization of benzoic acid. Int. J. Pharm.,1997; 348: 61-69.

2. Singh M, S Manikandan, AK Kumaraguru. Nanoparticles: A new technology with wide applications. Res. J. Nanosci. Nanotechnol.,2011; 1: 1-11.

3. Shangraw RF, Compressed tablets by direct compression. In Lieberman HA, Lachman L, Schwartz J. B. Pharmaceutical Dosage Forms: Tablets,Marcel Dekker, New York, 1989; 1:195-246.

4. Eros I, Goczo H, Szabo-Revesz P, Farkas B, Hasznos-Nezdei M, Serwanis FS, Pintye-Hodi K, Kasa P, Antal I, Marton S. Development of spherical crystals of acetyl salicylic acid for direct tablet making. Chem. Pharm. Bull, 2000; 48(12):1877-1881.

5. Gharaei-Fathabad, E. Biosurfactants in pharmaceutical industry: A mini-review. Am. J. Drug Discovery Dev, 2011; 1: 58-69.

6. Patil SV, Sahoo SK. Pharmaoverview of spherical crystallization. Der Pharmacia Lettre 2010; 2(1)421-426.

7. Sano A, Kuriki T, Kawashima Y, Takeuchi H, Hino T, Niwa T Particle design of tolbutamide by spherical crystallization tech. V. Improvement of dissolution and bioavailability of direct compressed tablets prepared using tolbutamide agglomerated crystals. Chem Pharm. Bull. 1992; 40:3030-3035.

8. MM Gupta, B Srivastava, M Sharma, V Arya. Int J Pharm Res Dev. 2010; 12(2):1-10.

9. N Bharti, N Bhandari, P Sharma, K Singh; A Kumar. Asian Jof Biomedical and Pharm Sci,2013; 18(3):10-16.

10. VB Yadav, AV Yadav.Trop J Pharm Res., 2009; 8(4):361-369.

11. A Nokhodchi, M Maghsoodi, D Hassanzadeh. Iran J Pharm Res., 2007; 6(2):83-93.

12. KR Mahadik, AP Pawar, AR Paradkar, S Kadam. AAPS Pharm Sci Tech., 2004; 5(3):1-8.

13. M Ueda, Y Nakamura, H Makita, Y Imasato, Y Kawashima. Chem Pharm Bull., 1990; 38(9):2537-2541.

14. A Sano, T Kuriki, Y Kawashima, H Takeuchi,THino; T Niwa. Chem Pharm Bull., 1992; 40 (10):3030-3035.

15. M Dixit, PK Kulkarni, PSC Bose, R Reddy. Int J of Pharm Res and Dev2010; 2(9):33-43.

16. Patil SV, Sahoo SK. Pharmoverview of spherical crystallization Res Library.Der Pharmacia Lettre, 2010; 2 (1): 421-426.

17. Kulkarni PK, Nagavi PG. Ind. Jr. Pharm. Eudc, 2002; 36(2):66-73. excellent physicochemical and micromeritic properties, solubility, dissolution rate, stability and in vivo (preclinical and clinical) performance when compared with pure drug as well as marketed formulation besides exhibiting no preclinical toxicity On the whole, spherical crystallization technique seems to be promising technique in which the drug crystals are changed by applying different solvents for obtaining direct compressible spherical agglomerates.

18. Jain SK, Chourasia MK, Jain NK, Jain S. Preparation and characterization of agglomerates of flurbiprofen by spherical crystallization Tech.Ind. J. Pharm. Sci, 2003; 65(3):287-291.

19. Deshpande MC, Mahadik KR, Pawar AP and Paradkar AR. Evaluation of spherical crystallization as particle size enlargement Tech for aspirin Ind.JPharmSci, 1997 59(1):32-34.

20. Jarosz PJ and Parrott EL. Compression of granule strength and tablet tensile strength. J Pharm. Sci, 72(5), 1983, 530-534

21. Bhadra S, Kumar M, Jain S, Agrawal S and Agrawal GR.Spherical crystallization of Mefenamic acid. Pharmaceutical Technology, 2004:66-76.

22. Chourasia MK, Jain SK, Jain S. and Jain NK. Preparation and characterization of agglomerates of Flurbiprofen by spherical crystallization technique. Ind. JPharm Sci, 2003:287-291.

23. Kaur H, Mariappan TT and Singh S. Behavior of uptake of moisture by drugs and excipients under accelerated conditions of temperature and humidity in the absence and presence of light, various drug substances, Part-III, 2009

24. Gupta VR, Srinivas M, Patel MM, Jani GK. Spherical crystals of Celecoxib to improve the solubility, dissolution rate and micromeritic properties. Acta Pharm. 2007; 57:173-184

25. Gohle MC, Parikh RK, Shen H, Rubey RR. Improvement in flowability and compressibility of Ampicilline Trihydrate by spherical crystallization. Ind J Pharm Sci. 2003; 634-37.

26. Hector GP, Jorge B, Carlo A. Preparation of Norfloxacin spherical agglomerates using the ammonia diffusion system. J Pharm Sci. 1998; 87(4):519-23.

27. Yadav VB, Yadav AV. Polymeric Recrystallized agglomerates of Cefuroxime Axetil prepared by Emulsion Solvent Diffusion Tech Trop. J Pharm. Res.2009; 8(4):361-369.

28. Yadav Venkat and Yadav Adhikrao; "Directly compressible roxithromycin recrystallizedagglomerates by solvent change Tech". Scholars Res Library der Pharmacia Lettre 2010; (1)2:25-40.

29. Deshpande M.C, Mahadik K.R, Pawar A.P, Paradkar A.R; "Evaluation of spherical crystallization as particle size enlargement Tech for Aspirin". IntJof PharmSci.1997; (1)53:32-34

30. N. Usha, S. Mutalik, M. S. Reddy and A. K. Ranjith, Preparation and, in vitro, preclinical and clinical studies of Aceclofenac spherical agglomerates, Eur. J. Pharm. Biopharm.2008;70:674-683

31. H. Goczo, P. Szabo-Revesz, B. Farkas, M. Hasznos-Nezdei, S.F. Serwanis, A.K. Pintye-Hodi, P. Kasa, Jr., I. Eros, I. Antal and S.Marto, Development of spherical crystals of acetylsalicylic acid for direct tablet-making, Chem. Pharm. Bull.2000; 48:1877-1881. 
32. Bausch A, Leuenberger $\mathrm{H}$. Wet spherical agglomeration of proteins as a new method to prepare parenteral fast soluble dosage forms. Int $\mathbf{J}$ Pharm. 1994; 101:63-70.

33. P. Di Martino, C. Barthelemy, F. Piva, E. Joiris, G. F. Palmieri and S Martelli, Improved dissolution behavior of fenbufen by spherical crystallization, Drug Dev. Ind. Pharm.1999; 25:1073-1081.

34. J bilou M, Ettabia A, Guyot-Hermann, AM, Guyot JS. Ibuprofen agglomeration prepared by phase separation. Drug Dev Ind Pharm. 1990; 25(3):297-305

35. Pawar, A. Paradkar, S. Kadam and K. Mahadik, Crystallo-coagglomeration: A novel technique to obtain ibuprofen-paracetamol agglomerates, AAPS Pharm.Sci.Tech.5, 2004):44.

36. Pawar, A. R. Paradkar, S. S. Kadam and K. R. Mahadik, Effect of polymers on crystallo-co-agglomeration of ibuprofen-paracetamol: Factorial design, Ind. J. Pharm. Sci. 2007; 69:658-664.

37. Pawar A, Paradkar A, Kadam S, Mahadik K. Agglomeration of Ibuprofen with Talc by Novel Crystallo-Co- Agglomeration Technique. AAPS Pharm SciTech, 2004; 5(4):1-6.

38. Mudit Dixit, PK Kulkarni1. Spherical agglomeration of Indomethacin by solvent change method. Int $\mathbf{J}$ of Pharma Res and Dev, 2005; 2(9):33-43.

39. Kawashima Y. Devof spherical crystallization tech and its application to pharmsystems. Arch Pharm. Res.1984; 7(2):145-151.

40. F. Espitalier, B. Biscans and C. Laguerie, Particle design Part B: batch quasi-emulsion process and mechanism of grain formation of ketoprofen, Chem. Eng. J.1997; 68:103-114.

41. Chavda V, Maheshwari RK. Tailoring of ketoprofen particle morphology via novel crystallo-coagglomeration technique to obtain a directly compressible material, Asian J. Pharm,2008; 2(1):61-67.

42. S. Bhadra, M. Kumar, S. Jain, S. Agrawal and G. P. Agrawal Spherical crystallization of mefenamic acid, Pharm. Technol. 2004: 66-76.

43. M. Maghsoodi, O. Taghizadeh, G. P. Martin and A. Nokhodchi, Particle design of naproxen-disintegrant agglomerates for direct compression byacrystallo-co-agglomeration Tech, IntJPharm.2008; 351:45-54.

44. Viswanathan CL, Kulkarni SK, Kolwankar DR. Spherical agglomeration of mefenamic acid and Nabumetone to improve micromeritics and solubility: A Technical AAPS Pharm Sci Tech.2006; 7(2):48.
45. M Dixit, PK Kulkarni. Preparation and characterization of spherical agglomerates of Piroxicam by neutralization method. American $\mathbf{J}$ of drug discovery and dev, 2011:1-12.

46. Martino P.D, Cristofaro R.D, Joiris E., Filippo G.P, Sante M; "Improved compression properties of propyphenazone spherical crystals", IntJ of Pharm 2000; 197:95-106.

47. Kawashima Y, Aoki S, Takenaka H, Miyake Y; "Preparation of spherically agglomerated crystals of aminophylline". Jof PharmSci 1984; (10)73:1407-10.

48. Bos AS, Zuiderweg FJ. Size of agglomerates in batch wise suspension agglomeration. Chem Eng Res Des. 1987; 65a: 187.

49. Bermer GG, Zuiderweg FG. Proceedings of international symposium of fine particles. AIME. 1992:1524-46.

50. Sano, T. Kuriki, Y. Kawashima, T. Hino and T. Niwa, Particle design of tolbutamide by the spherical crystallization technique. III. Micromeritic properties and dissolution rate of tolbutamide spherical agglomerates prepared by the quasi-emulsion solvent diffusion method and the solvent change method, Chem. Pharm. Bull.1990; 38:733-739.

51. Kawashima Y, Cui F, Takeuchi H, Niwa T, Hino T, Kiuchi K. Parameters determining the agglomeration behavior and the micromeritic properties of spherically agglomerated crystals prepared by the spherical crystallization technique with miscible solvent systems. Int. J. Pharm, 1995; 119(2):139-147.

52. Yadav VB, Yadav AV. Effect of Different Stabilizers and Polymers on Spherical Agglomerates of Gresiofulvine by Emulsion Solvent Diffusion (ESD) System. Int. J. Pharm. Tech. Res., 2009; 1(2):149150 .

53. Kawashima Y, Niwa T, Takeuchi H, Hino T, Itoh Y, Furuyama S, Characterization of polymorphs of Tranilast anhydrate and Tranilast monohydrate when crystallization by two solvents changes spherical crystallization Tech. J. Pharm. Sci., 1991; 80(5):472-78.

54. Miss Bhosale Bhakti Bhimarao, Mr. D. M. Shivale Preparation and characterization of spherical crystals of valsartan for direct compression method Int J of Pharm Res and Dev, 2009; 1:4.

55. Kumar S, Chawla G, Bansal A. Spherical Crystallization of Mebendazole to Improve Processability. Pharm. Dev. Technol.2008; 13(6):559-568 